\title{
Impact of Gene-Gender Effects of Adrenergic Polymorphisms on Hypothalamic-Pituitary- Adrenal Axis Activity in Depressed Patients
}

\author{
S. Haefner T.C.Baghai C.Schule D. Eser M.Spraul P. Zill R. Rupprecht \\ B. Bondy
}

Department of Psychiatry and Psychotherapy, Ludwig Maximilian University of Munich, Munich, Germany

\section{Key Words}

Depression - Dexamethasone suppression test $\cdot$ HPA axis • Adrenoreceptors $\cdot$ Genetic polymorphism $\cdot$ Gene-gender effects

\begin{abstract}
Objective: There is overwhelming evidence that activation of the hypothalamic-pituitary-adrenal (HPA) system plays a major role in depression and cardiovascular disease in genetically susceptible individuals. We hypothesized that due to the multiple interactions between the sympathetic and the HPA systems via adrenoceptors, polymorphisms in these genes could have an impact on HPA axis activity in major depression. Methods: Using the dexamethasone/corticotrophin-releasing hormone (DEX/CRH) test, we investigated the association of $\alpha_{2}$-adrenoceptor (ADRA2A $-1291 \mathrm{C} \rightarrow \mathrm{G}$ ) and the $\beta_{2}$-adrenoceptor gene (ADRB2 Arg16Gly) in 189 patients with major depression during the acute state of the disease and after remission. Results: Male ADRA2A -1291G allele homozygotes showed significant pretreatment HPA axis hyperactivity, with increased adrenocorticotropin $(\mathrm{ACTH} ; \mathrm{F}=4.9$, d.f. $=2, \mathrm{p}=0.009)$ and cortisol responses $(\mathrm{F}=$ 6.4 , d.f. $=2, p=0.003$ ). In contrast, female ADRB2 Arg/Arg homozygotes had increased pretreatment ACTH ( $F=7.17$, d.f. $=2, p=0.001)$ and cortisol $(F=8.95$, d.f. $=2, p=0.000)$ levels. Interestingly, in the respective genotypes, the stress
\end{abstract}

hormones remained elevated in the second DEX/CRH test, despite a reduction in depressive symptoms. Conclusions: This study provides evidence that, depending on gender and polymorphisms, there is continuous HPA axis overdrive in a proportion of patients irrespective of the status of depression. Considering the importance of stress hormones for cardiovascular disorders, our data might suggest that these patients are at high risk of comorbidity between depression and cardiovascular disorders. Copyright $\odot 2008$ S. Karger AG, Basel

\section{Introduction}

There is substantial evidence that alterations within neuroendocrine systems play a major role in complex stress-related psychiatric and somatic disorders. Dysfunctions of the hypothalamic-pituitary-adrenal (HPA) axis, with enhanced releases of corticotrophin-releasing hormone (CRH), adrenocorticotropin (ACTH) and cortisol, influence many functions of the central nervous system, such as arousal, cognition, sleep, the maintenance of a normal cardiovascular tone, as well as the activity and quality of immune and inflammatory reactions [1]. On the other hand, cortisol hypersecretion may also enhance the central accumulation of body fat, dyslipidaemia or hypertension [2,3]. Thus, dysregulations

\section{KARGER}

Fax +4161306 1234

E-Mail karger@karger.ch

www.karger.com
(C) 2008 S. Karger AG, Base

0302-282X/08/0584-0154\$24.50/0

Accessible online at:

www.karger.com/nps
Prof. Brigitta Bondy, MD, Department of Psychiatry and Psychotherapy

Ludwig Maximilian University of Munich

Nussbaumstrasse 7, DE-80336 Munich (Germany)

Tel. +49 895160 2737, Fax +498951604741

E-Mail brigitta.bondy@med.uni-muenchen.de 
within the HPA and the closely related sympatho-adrenal-medullary (SAM) axes might have tremendous effects on both the central nervous and cardiovascular systems. Today, there is no doubt about the deleterious effects of a comorbidity between depression and coronary artery disease, with about a 3-fold increase in morbidity and mortality [4]. One of the repeatedly discussed common pathophysiological mechanisms for this comorbidity is the impact of stress and the neuroendocrine hormones on the different organs [4].

Stressful life events activate the HPA axis and the adrenergic and autonomic nervous systems with lots of interactions between them at different levels [5]. The sympathetic and CRH neurons are reciprocally connected, and thus contribute to the body's response to stressful stimuli. As CRH further alters the noradrenergic activity in locus coeruleus neurons, dysfunction of catecholaminergic neurons has been implicated in the pathophysiology of affective and stress-related disorders [6].

Alterations in the HPA axis may be revealed in the combined DEX/CRH test demonstrating insufficient cortisol suppression and increased ACTH release in a significant proportion of depressed patients [7]. As these alterations partially persist after successful treatment with remission and abnormal levels of ACTH may be observed even in asymptomatic first-degree relatives of depressed patients [8], a genetic contribution to the regulation of the HPA axis has been suggested.

Among the candidate genes determining the interaction and regulation of both systems, those involved in the regulation of catecholamine function may be of particular importance. Common single nucleotide polymorphisms (SNPs) in adrenergic receptor genes were shown as susceptibility loci for obesity, metabolic alterations [9] and cardiovascular disorders [10]. Further, dysfunctions in the noradrenergic system might comprise a significant vulnerability trait to develop depression [11]. The $\alpha_{2}$-adrenoceptors (ADRA2A) are not involved in the control of the HPA axis under basal conditions but exert an inhibitory effect as a negative feedback mechanism, and thus limit excessive activation [12]. Recently, a $-1291 \mathrm{C} \rightarrow \mathrm{G}$ polymorphism in the promoter region of the ADRA2A gene was associated with subnormal cortisol response to dexamethasone and elevated glucose levels, suggesting a genetic impact on the SAM-HPA axis interaction [13]. Another gene of interest is that coding for the $\beta_{2}$-adrenoceptor (ADRB2), as the secretion of ACTH in the anterior pituitary is stimulated by noradrenaline via this receptor [14]. A common polymorphism in the ADRB2 gene causes a change in the amino acids at residues 16
(Arg16Gly), which has been associated with a 5-fold increase in receptor sensitivity [15]. The Arg16 allele was related to hypertension and obesity in 1 study [16], associated with the Gly allele in another [17], and no relation with either of the alleles was observed in another [18].

As discussed, chronic stress induces activation of the HPA and SAM axes leading to cardiovascular disease and depression in genetically susceptible individuals [19]. As there are several interactions between these 2 axes via $\alpha$ and $\beta$-adrenoceptors, we investigated the effects of the ADR2A $(-1291 \mathrm{C} \rightarrow \mathrm{G})$ and ADRB2 (Arg16Gly) polymorphisms using the combined DEX/CRH test in patients with major depression.

\section{Methods}

Patients

One hundred and eighty-nine (86 males, 103 females, mean age $47.5 \pm 13.1$ years) suffering from a major depressive episode according to DSM-IV criteria were enrolled in the study. Patients with major medical disorders, addictions or other comorbid psychiatric disorders were excluded. In $2.5 \%$ of the patients, hypertension was known and the patients were continuously treated with anti-hypertensive medication. All patients were white Caucasians of German descent.

Pretreatment with carbamazepine, depot antipsychotics, hormone replacement therapy or fluoxetine were further exclusion criteria to avoid interference with endocrinological testing. None of the female patients were taking oral contraceptives. The severity of depression was assessed with the 17-item Hamilton Rating Scale for Depression (HRSD-17) by experienced psychiatrists who were blind to hormonal measurements and genotyping. Patients received either various classes of psychopharmacological drugs or non-pharmacological therapies as an acute treatment. These included repetitive transcranial magnetic stimulation (25.2\%), electroconvulsive therapy (13.0\%), tricyclic $(12.2 \%)$ or non-tricyclic antidepressants $(50.4 \%$ mirtazapine, $13.0 \%$ selective serotoninreuptake inhibitors, $7.0 \%$ venlafaxine, $0.9 \%$ moclobemide) and combinations; $26.1 \%$ received neuroleptics due to mood-congruent psychotic features. Laboratory parameters and clinical variables such as blood pressure, heart rate and body mass index were monitored in all patients at the time of the first DEX/CRH test, and in 86 of them at the second DEX/CRH test. Clinical and demographic characteristics of the depressed patients at admission are presented in table 1.

The study was carried out according to the Declaration of Helsinki (http://www.wma.net) and had been approved by the local ethics committee. After a complete description of the study to the subjects, written informed consent was obtained.

\section{Combined DEX/CRH Test}

In all patients, the combined DEX/CRH suppression test was performed, following a washout period of at least 5 days after admission. Participants received 1.5 mg DEX at 23:00 h. On the following day, an intravenous catheter was inserted before 14:15 h 
Table 1. Demographic, clinical characteristics and ADRA2A $-1291 \mathrm{C} \rightarrow \mathrm{G}$ and ADRB2 Arg16Gly genotypes in patients with major depression, according to gender

\begin{tabular}{|c|c|c|c|c|}
\hline & $\begin{array}{l}\text { All patients } \\
(\mathrm{n}=189)\end{array}$ & $\begin{array}{l}\text { Males } \\
(\mathrm{n}=86)\end{array}$ & $\begin{array}{l}\text { Females } \\
(\mathrm{n}=103)\end{array}$ & $\begin{array}{l}\text { Significance } \\
\text { (males vs. females) }\end{array}$ \\
\hline Age, years & $47.5 \pm 13.1$ & $46.9 \pm 12.2$ & $47.9 \pm 13.8$ & n.s. \\
\hline HRSD-17, week 0 & $25.1 \pm 5.8$ & $24.8 \pm 5.6$ & $25.2 \pm 6.0$ & n.s. \\
\hline HRSD-17, discharge & $8.5 \pm 5.0$ & $8.3 \pm 4.8$ & $8.6 \pm 5.2$ & n.s. \\
\hline Duration of inpatient status, days & $72.1 \pm 45.4$ & $73.3 \pm 36.9$ & $70.9 \pm 51.4$ & n.s. \\
\hline Weight, kg & $72.8 \pm 13.4$ & $78.7 \pm 12.3$ & $67.4 \pm 12.1$ & $\mathrm{Z}=-5.1, \mathrm{p}=0.000$ \\
\hline BMI & $24.9 \pm 3.9$ & $25.3 \pm 3.6$ & $24.5 \pm 4.1$ & n.s. \\
\hline Systolic BP, mm Hg & $133.6 \pm 17.6$ & $135.58 \pm 17.3$ & $131.8 \pm 17.8$ & n.s. \\
\hline Diastolic BP, mm Hg & $87.7 \pm 10.9$ & $85.2 \pm 10.9$ & $84.5 \pm 11.0$ & n.s. \\
\hline Heart rate, beats/min & $85.7 \pm 12.8$ & $85.5 \pm 11.6$ & $86.8 \pm 13.9$ & n.s. \\
\hline Cholesterol, mg/dl & $221.4 \pm 42.3$ & $221.4 \pm 43.3$ & $221.5 \pm 41.8$ & n.s. \\
\hline Triglycerides, mg/dl & $139.1 \pm 79.8$ & $164.2 \pm 94.22$ & $118.8 \pm 59.3$ & $Z=-2.7, p=0.005$ \\
\hline Fasting glucose, $\mathrm{mg} / \mathrm{ml}$ & $99.35 \pm 21.65$ & $101.5 \pm 22.1$ & $97.6 \pm 21.4$ & n.s. \\
\hline Cortisol (1st DEX/CRH test: AUC), ng/ml & $294.49 \pm 304.0$ & $281.7 \pm 277$ & $305.1 \pm 325.5$ & n.s. \\
\hline ACTH (1st DEX/CRH test: AUC), pg/ml & $1,128.1 \pm 1,083.9$ & $1,228.4 \pm 1,141.8$ & $1,044.4 \pm 1,031.4$ & n.s. \\
\hline \multicolumn{5}{|l|}{ ADRA2A $-1291 C \rightarrow G$} \\
\hline $\mathrm{C} / \mathrm{C}$ & $117(62.9)$ & $51(59.3)$ & $66(64.1)$ & n.s. ${ }^{1}$ \\
\hline $\mathrm{C} / \mathrm{G}$ & $61(32.3)$ & $29(33.7)$ & $32(31.1)$ & \\
\hline $\mathrm{G} / \mathrm{G}$ & $11(5.9)$ & $6(7.0)$ & $5(4.9)$ & \\
\hline Frequency C, \% & 78 & 76 & 80 & n.s. ${ }^{2}$ \\
\hline Frequency G, \% & 22 & 24 & 20 & \\
\hline \multicolumn{5}{|l|}{ ADRB2 Gly16Arg } \\
\hline Gly/Gly & $74(39.2)$ & $32(37.2)$ & $42(40.8)$ & n.s. ${ }^{1}$ \\
\hline Gly/Arg & $89(47.1)$ & $42(48.8)$ & $47(45.6)$ & \\
\hline Arg/Arg & $26(13.8)$ & $12(14)$ & $14(16.6)$ & \\
\hline Frequency Gly, \% & 63 & 62 & 64 & n.s. ${ }^{2}$ \\
\hline Frequency Arg, \% & 37 & 38 & 36 & \\
\hline
\end{tabular}

Figures in parentheses are percentages. AUC $=$ Area under the curve.

${ }^{1} \chi^{2}$ test. ${ }^{2}$ Fisher's exact test.

and blood samples were collected at 15:00, 15:15, 15:30, 15:45, 16:00 and $16: 15 \mathrm{~h}$, immediately centrifuged and stored at $-80^{\circ} \mathrm{C}$ for cortisol and ACTH measurements. At 15:00 h, $100 \mu \mathrm{g}$ human corticotropin-releasing hormone (hCRH; Clinalfa, Läufelfingen, Switzerland) were injected within $30 \mathrm{~s}$. Serum cortisol levels were determined with an immunoassay analyzer (Elecsys Cortisol Test; Roche Diagnostics, Mannheim, Germany) and ACTH plasma concentrations with a commercially available immunoradiometric assay (ACTH 100T Kit; Nichols Institute Diagnostics, San Juan Capistrano, Calif., USA). In 170 of the patients, the DEX/ $\mathrm{CRH}$ test was rerun before discharge from hospital.

\section{Genotyping of ADR2A $-1291 C \rightarrow G$ and ADRB2 Arg16Gly}

Polymorphisms

Genomic DNA was isolated from whole blood according to standard procedures. Genotyping of the ADRB2 polymorphism (Arg16Gly, rs1042713) was performed by the fluorescence resonance energy transfer method using the Light Cycler System (Roche Diagnostics). The following conditions were applied: forward primer: 5'-GAC AAG CTG AGT GTG CAG GA-3'; reverse primer: 5'-AAC TTG GCA ATG GCT GTG AT-3'; donor hybridization probe: 5'-CGT CAC GCA GCA AAG GGA-fluorescein-3'; acceptor hybridization probe: 5'-LCRed640-AGG TGT GGG TGG TGG GCA TGG GCA RCG TCA TGT-3'. PCR was performed with $50 \mathrm{ng}$ DNA (total volume $20 \mu \mathrm{l}$ ) containing $2 \mu \mathrm{l}$ reaction mix, $0.5 \mu \mathrm{M}$ each primer, $0.2 \mu \mathrm{M}$ each hybridization probe and $2 \mu \mathrm{M} \mathrm{MgCl}_{2}$ according to the manufactures instructions for 35 cycles of denaturation $\left(95^{\circ} \mathrm{C}, 0 \mathrm{~s}\right.$, ramp rate $\left.20^{\circ} \mathrm{C} / \mathrm{s}\right)$, annealing $\left(65^{\circ} \mathrm{C}, 10 \mathrm{~s}\right.$, ramp rate $\left.20^{\circ} \mathrm{C} / \mathrm{s}\right)$ and extension $\left(72^{\circ} \mathrm{C}, 10 \mathrm{~s}\right.$, ramp rate $20^{\circ} \mathrm{C} / \mathrm{s}$ ). After amplification, a melting curve was generated by holding the reaction at $40^{\circ} \mathrm{C}$ for $20 \mathrm{~s}$ and then heating slowly to $95^{\circ} \mathrm{C}$ with a ramp rate of $0.2^{\circ} \mathrm{C} / \mathrm{s}$. The fluorescence signal was plotted against temperature to give melting curves for each sample. The following peaks were obtained: $61^{\circ} \mathrm{C}$ for the A allele (Arg) and $50^{\circ} \mathrm{C}$ for the $\mathrm{G}$ allele (Gly). The $-1291 \mathrm{C} \rightarrow \mathrm{G}$ SNP in the ADRA2A (rs1800544) gene was detected as a restriction fragment length polymorphism, as described by Rosmond et al. [13]. The genotyping results were checked by comparison with published genotype and allele frequencies from the literature. Moreover, each genotyping was performed with internal controls from the 


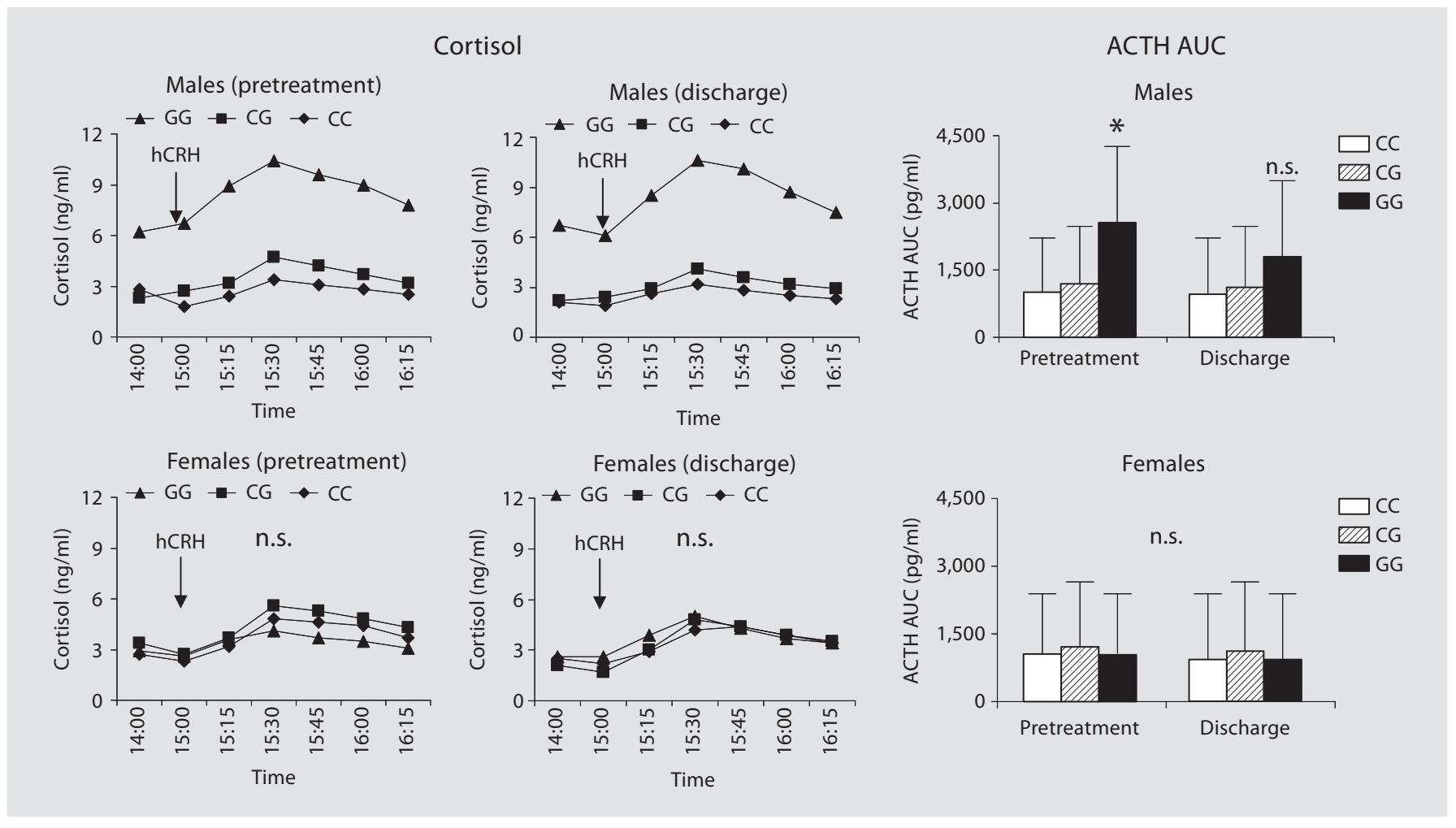

Fig. 1. Mean serum cortisol and ACTH concentrations in the $\mathrm{DEX} / \mathrm{CRH}$ test in male and female patients with major depression in relation to the ADRA2A $-1291 \mathrm{C} \rightarrow \mathrm{G}$ polymorphism. DEX/ $\mathrm{CRH}$ tests were performed twice, during the acute state of depression (86 males, 103 females) and before discharge from hospital (77 males, 93 females). Repeated measurement ANOVA of the pretreatment DEX/CRH test showed in 6 male -1291GG carriers a significant increase in cortisol levels $(F=6.4$, d.f. $=2, p=0.003)$ and ACTH - AUC levels (Kruskal-Wallis test: $\chi^{2}=7.3$, d.f. $=2$, $\left.{ }^{*} \mathrm{p}=0.026\right)$, which remained elevated in the last DEX/CRH test, before discharge. In the male CG $(n=29)$ and CC $(n=51)$ carriers there was no significant difference concerning the cortisol and ACTH values. Also in 103 females there was no significant relation between genotypes and the parameters of the DEX/CRH test. previous experiments. Therefore, we can exclude genotyping errors to a very high degree. With this approach, error rates were smaller than $1 \%$. These samples were excluded from the analysis. The call rates were greater than $98 \%$. All laboratory procedures were carried out blind to case control status.

\section{Statistical Analyses}

Deviation from Hardy-Weinberg equilibrium was tested using a $\chi^{2}$ test ( 1 d.f.). Differences in genotype and allele frequencies between patients and controls and between genders were calculated with the $\chi^{2}$ test and Fisher's exact test, respectively. Mean differences in demographic and clinical variables between males and females were compared using the non-parametric MannWhitney test. To evaluate significant time effects on cortisol and ACTH concentrations during the DEX/CRH test, ANOVAs for repeated measurements were performed using 'time' (repeated hormonal measurements at the time points 15:00, 15:15, 15:30, $15: 45,16: 00$ and 16:15 h) as the within-subjects factor with 6 levels, genotypes as the between-subjects factor with 3 levels and age as a covariate. To approach normality and homogeneity in the data, hormonal concentrations were transformed with the log transformation before entering the analysis. Mean differences for cortisol and ACTH area under curve (AUC) values as well as several clinical characteristics, such as blood pressure, heart rate and serum lipids between different genotypes were compared using the non-parametric Kruskal-Wallis test. The level of significance was set at 0.05 . Statistical analysis was performed using SPSS for Windows (release 15.0; SPSS, Chicago, Ill., USA).

\section{Results}

We carried out the combined DEX/CRH test in 189 patients with an acute episode of major depression after admission to the hospital, and repeated this investigation in 170 of them before discharge. The ACTH and cortisol values were correlated with clinical variables; in addition, differences in dependency of the genotypes of the ADRA2A 
$-1291 \mathrm{C} \rightarrow \mathrm{G}$ and the ADRB2 Arg16Gly polymorphisms were investigated. All genotypes were in Hardy-Weinberg equilibrium and the genotype and allele frequencies were similar to those reported earlier [13, 15] (table 1), without gender differences for both polymorphisms.

The mean HRSD-17 score dropped from $25.1 \pm 5.8$ to $8.5 \pm 5.0$ between the first and the second DEX/CRH test (table 1), which means a $66 \%$ overall reduction in depressive symptoms. Assuming a minimum of $50 \%$ score reduction as response criterion, $82.4 \%$ of the patients may be classified as responders at the time of discharge from hospital. We could not observe gender differences concerning the severity of symptoms (HRSD-17) or the duration of inpatient status, blood pressure and heart rate. Concerning weight and serum triglycerides, we observed significantly higher values in the male patient group at the time of hospitalization. Basal and stimulated cortisol and ACTH levels of the first DEX/CRH test (both expressed as AUC did not vary significantly between males and females; table 1).

Using ANOVA for repeated measurements, significant effects in the DEX/CRH test results could be demonstrated. In the total patient group, there were significant 'time' effects for both ACTH $(\mathrm{F}=56.4$, d.f. $=2$, $\mathrm{p}<$ $0.001)$ and cortisol $(\mathrm{F}=76.9$, d.f. $=2, \mathrm{p}<0.001)$, indicating significant increases in HPA axis hormones after hCRH injection.

These effects were further influenced by the different genotypes investigated. The pretreatment DEX/CRH test (repeated-measures ANOVA) showed, in the 6 male patients homozygous for the ADRA2A -1291G allele, a significant increase in cortisol (fig. 1 : $\mathrm{F}=6.4$, d.f. $=2, \mathrm{p}=$ $0.003)$ and $\mathrm{ACTH}(\mathrm{F}=4.9$, d.f. $=2, \mathrm{p}=0.009)$ response. Correspondingly, the cortisol AUC levels in males were $762 \pm 475 \mathrm{ng} / \mathrm{ml}$ in GG genotypes, $293 \pm 242 \mathrm{ng} / \mathrm{ml}$ in GC genotypes and $218 \pm 207 \mathrm{ng} / \mathrm{ml}$ in CC genotypes (Kruskal-Wallis test: $\chi^{2}=9.04$, d.f. $=2, p=0.011$ ). Only 1 of these GG carriers had a cortisol AUC value in the mean range of the CG and CC genotypes $(220 \mathrm{ng} / \mathrm{ml})$; in the other five ADRA2A-GG patients, the cortisol AUC values ranged from 400 to $1,480 \mathrm{ng} / \mathrm{ml}$. Also, the ACTH AUC values were significantly elevated in the male GG genotypes $(2,566 \pm 1,770 \mathrm{pg} / \mathrm{ml})$, in contrast to the GC $(1,195 \pm 927 \mathrm{pg} / \mathrm{ml})$ and CC carriers $(1,007 \pm 1,012 \mathrm{pg} /$ ml; Kruskal-Wallis test: $\chi^{2}=7.29$, d.f. $\left.=2, p=0.026\right)$. Interestingly, the cortisol AUCs remained significantly elevated in the male GG carriers at the time of discharge from hospital $\left(\chi^{2}=7.09\right.$, d.f. $\left.=2, p=0.029\right)$. In contrast, in the female patient group $(n=108)$ we observed no significant relation between the ADRA2A genotypes and the time effects of ACTH or cortisol before treatment (ACTH: $\mathrm{F}=0.011$, d.f. $=2, \mathrm{p}=0.98$; cortisol: $\mathrm{F}=0.095$, d.f. $=2, p=0.90)$ or before discharge (ACTH: $F=0.017$, d.f. $=2, p=0.98$; cortisol: $F=0.26$, d.f. $=2, p=0.77$ ).

Concerning the ADRB2 Arg16Gly polymorphism, we found increased HPA axis activity using repeated-measures ANOVA in females carrying at least one 16Arg allele, with highest pretreatment ACTH $(\mathrm{F}=7.17$, d.f. $=2$, $\mathrm{p}=0.001)$ and cortisol curves $(\mathrm{F}=8.95$, d.f. $=2, \mathrm{p}=0.000)$ in Arg/Arg genotypes (fig. 2). The cortisol and AUC values were $575 \pm 140 \mathrm{ng} / \mathrm{ml}$ in Arg/Arg genotypes, $356 \pm$ $321 \mathrm{ng} / \mathrm{ml}$ in Arg/Gly genotypes and $188 \pm 250 \mathrm{ng} / \mathrm{ml}$ in Gly/Gly genotypes (Kruskal-Wallis test: $\chi^{2}=15.8$, d.f. $=$ $2, \mathrm{p}=0.000)$. ACTH values were: $1,775 \pm 1,291 \mathrm{pg} / \mathrm{ml}$ in Arg/Arg genotypes, $1,283 \pm 1,208 \mathrm{pg} / \mathrm{ml}$ in Arg/Gly and $683 \pm 806 \mathrm{pg} / \mathrm{ml}$ in Gly/Gly genotypes (Kruskal-Wallis test $\chi^{2}=14.3$, d.f. $\left.=2, p=0.001\right)$. Although the overall values were slightly decreased in the last observation, there was still a significant effect of the ADRB2 Arg16Gly polymorphism in female, but not in male, patients (ACTH: $\mathrm{F}=4.31$, d.f. $=2, \mathrm{p}=0.017$; cortisol: $\mathrm{F}=5.57$, d.f. $=2, \mathrm{p}=$ $0.005)$. In males, no genotype related differences were observed for the ACTH DEX/CRH $(\mathrm{F}=2.04$. d.f. $=2, \mathrm{p}=$ $0.114)$ or cortisol curves $(\mathrm{F}=1.86$, d.f. $=2, \mathrm{p}=0.162)$. In table 2 some clinical data are listed in relation to the ADRA2A $-1291 \mathrm{C} \rightarrow \mathrm{G}$ and ADRB2 Arg16Gly genotypes. We were unable to identify any association between genotypes and the baseline levels of BMI, serum lipids, fasting glucose, blood pressure or heart rate. In $45 \%(n=86)$ of the patients, these clinical parameters were again monitored at the time of the second DEX/CRH test, but no significant differences were obtained between the first and second measurement, and again there was no relation to the investigated genotypes. Although we observed a slight increase in the BMI from $24.9 \pm 3.8$ to $25.1 \pm$ 4.2 , this failed to reach significance. We observed a small but significant correlation between the cortisol AUC values of the pretreatment DEX/CRH test to the baseline HRSD-17 values (Spearman's correlation: $\rho=0.157, p=$ 0.035). After Bonferroni correction for multiple testing, only a non-significant trend to the relatively weak correlation could be detected. In males homozygous for the ADRA2A $-1291 \mathrm{G}$ allele, a mean decrease of only $41.2 \%$ in HRSD-17 score was observed, compared to decreases of 70.3 and $64.0 \%$ in the CG and CC genotypes, respectively, but this finding failed to reach significance (Kruskal-Wallis test $\chi^{2}=4.1$, d.f. $=2, p=0.12$ ), probably due to the low number of GG patients. There were no other clinical variables which differentiated the male ADRA2A GG carriers from the other patients. 


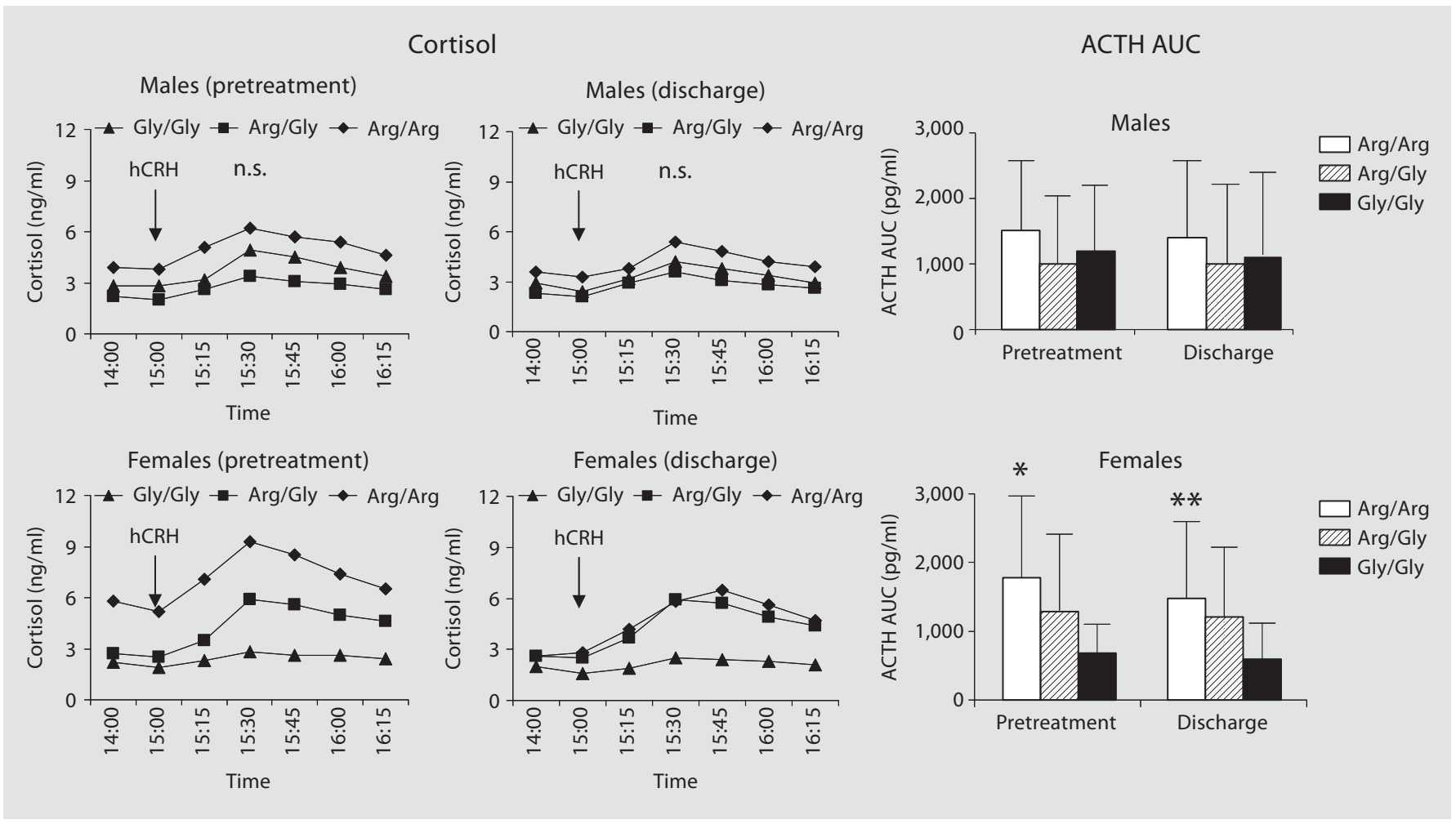

Fig. 2. Mean serum cortisol and ACTH concentrations in the DEX/CRH test in male and female patients with major depression in relation to the ADRB2 Gly16Ser polymorphism. DEX/CRH tests were performed twice, during the acute state of depression (86 males, 103 females) and before discharge from hospital (77 males, 93 females). Repeated measurement ANOVA of the pretreatment and the last DEX/CRH test showed no significant relation between genotypes and hormone concentrations in male patients. In females carrying at least one 16Arg allele $(n=61)$, HPA axis activity was increased, with highest pretreatment cortisol response (repeated measurement ANOVA: $\mathrm{F}=8.9$, d.f. $=2, \mathrm{p}=$ 0.000) and ACTH-AUC values in Arg/Arg genotypes (KruskalWallis test: $\chi^{2}=13.9$, d.f. $=2,{ }^{*} \mathrm{p}=0.001$ ). The overall ACTH AUC values and cortisol response curves were slightly decreased in the last observation but still significantly elevated in female Arg/Arg genotyopes (ACTH: $\chi^{2}=10.8$, d.f. $=2,{ }^{* *} \mathrm{p}=0.004$; cortisol: $\mathrm{F}=$ 5.5, d.f. $=2, \mathrm{p}=0.005)$
In the female patient group, there was no relation between the ADRA2A genotypes and treatment response (Kruskal-Wallis test $\chi^{2}=1.0$, d.f. $=2, \mathrm{p}=0.57$ ) and an overall response of about a $65 \%$ reduction in depressive symptoms was observed in all genotypes. Concerning the ADRB2 genotypes and the response to treatment, there was no relation to treatment response in the male or female patient group (table 2).

In order to differentiate between pre- and post-menopausal women, we split the female patients into those below 50 years of age $(n=54)$ and those above 50 years $(n=$ 49). No significant differences between these 2 groups were observed concerning the distribution of the ADRB2 Arg16Gly genotypes $\left(\chi^{2}=0.29\right.$, d.f. $\left.=2, p=0.86\right)$, the severity of baseline depressive symptoms or the response to treatment. However, we observed significant differences in systolic $(Z=-3.11, p=0.002)$ and diastolic blood pressure $(Z=-3.93, p=0.04)$ as well as in serum cholesterol $(Z=-3.93, p=0.000)$ and triglyceride values $(Z=-2.29$, $\mathrm{p}=0.022$ ), with higher values in women above 50 years of age (systolic blood pressure, $<50$ years: $125 \pm 19 \mathrm{~mm}$ $\mathrm{Hg},>50$ years: $136 \pm 16 \mathrm{~mm} \mathrm{Hg}$; diastolic blood pressure, $<50$ years: $201 \pm 39 \mathrm{mg} / \mathrm{dl},>50$ years: $235 \pm 30$ $\mathrm{mg} / \mathrm{dl}$; triglycerides, $<50$ years: $102 \pm 47 \mathrm{mg} / \mathrm{dl},>50$ years: $129 \pm 49 \mathrm{mg} / \mathrm{dl}$ ). Concerning the ACTH and cortisol curves, we observed higher values in the pretreatment DEX/CRH test in women beyond the age of 50 years, which, however, just failed significance (ACTH: $\mathrm{F}=3.08$, d.f. $=2, \mathrm{p}=0.082$; cortisol: $\mathrm{F}=2.94$, d.f. $=2$, $\mathrm{p}=0.089$ ). At the time of the second Dex/CRH test, there was no relation between the ACTH and cortisol curves and the age being below or above 50 years in females. 
Table 2. Clinical data in relation to the ADRA2A $-1291 \mathrm{C} \rightarrow \mathrm{G}$ and ADRB2 Arg16Gly polymorphisms

\begin{tabular}{|c|c|c|c|c|c|c|c|c|}
\hline & $\begin{array}{l}\text { HRSD-17 } \\
\text { basal score }\end{array}$ & $\begin{array}{l}\text { HRSD-17 } \\
\text { decrease, \% }\end{array}$ & BMI & $\begin{array}{l}\text { Cholesterol } \\
\mathrm{mg} / \mathrm{dl}\end{array}$ & $\begin{array}{l}\text { Triglycerides } \\
\mathrm{mg} / \mathrm{dl}\end{array}$ & $\begin{array}{l}\text { Systolic BP } \\
\mathrm{mm} \mathrm{Hg}\end{array}$ & $\begin{array}{l}\text { Diastolic BP } \\
\mathrm{mm} \mathrm{Hg}\end{array}$ & $\begin{array}{l}\text { HR, beats/ } \\
\text { min }\end{array}$ \\
\hline \multicolumn{9}{|c|}{$A D R A 2 A-1291 C \rightarrow G$} \\
\hline \multicolumn{9}{|c|}{ All patients $(\mathrm{n}=189)$} \\
\hline $\mathrm{CC}$ & $25.5 \pm 5.9$ & $63.4 \pm 23.1$ & $25.2 \pm 3.9$ & $222 \pm 38$ & $130 \pm 65$ & $132 \pm 18$ & $82 \pm 10$ & $83 \pm 12$ \\
\hline CG & $24.8 \pm 5.5$ & $69.3 \pm 17.3$ & $24.5 \pm 4.1$ & $220 \pm 48$ & $150 \pm 95$ & $131 \pm 18$ & $82 \pm 10$ & $84 \pm 10$ \\
\hline \multirow[t]{2}{*}{ GG } & $24.7 \pm 6.8$ & $53.2 \pm 33.0$ & $25.2 \pm 4.2$ & $240 \pm 32$ & $137 \pm 71$ & $132 \pm 20$ & $80 \pm 11$ & $82 \pm 9$ \\
\hline & n.s & $\mathrm{F}=3.1 ; \mathrm{p}=0.044$ & n.s. & n.s. & n.s. & n.s. & n.s. & n.s. \\
\hline \multicolumn{9}{|c|}{ Males $(n=86)$} \\
\hline $\mathrm{CC}$ & $25.2 \pm 5.7$ & $64.1 \pm 23.2$ & $25.9 \pm 3.4$ & $228 \pm 37$ & $160 \pm 76$ & $134 \pm 18$ & $82 \pm 9$ & $81 \pm 14$ \\
\hline CG & $24.6 \pm 4.8$ & $70.39 \pm 15$ & $25.0 \pm 4.1$ & $206 \pm 48$ & $177 \pm 86$ & $133 \pm 18$ & $83 \pm 9$ & $84 \pm 9$ \\
\hline \multirow[t]{2}{*}{ GG } & $22.3 \pm 6.3$ & $41.2 \pm 39$ & $24.0 \pm 3.1$ & $251 \pm 30$ & $158 \pm 48$ & $129 \pm 19$ & $81 \pm 10$ & $81 \pm 9$ \\
\hline & n.s. & $\mathrm{F}=4.6 ; \mathrm{p}=0.012$ & n.s. & n.s. & n.s. & n.s. & n.s. & n.s. \\
\hline \multicolumn{9}{|c|}{ ADRB2 Arg16Gly } \\
\hline \multicolumn{9}{|c|}{ All patients $(\mathrm{n}=189)$} \\
\hline Gly/Gly & $25.3 \pm 5.8$ & $66.2 \pm 24.4$ & $25.2 \pm 1.1$ & $220 \pm 46$ & $132 \pm 67$ & $134 \pm 16$ & $84 \pm 8$ & $83 \pm 12$ \\
\hline Gly/Arg & $24.5 \pm 5.8$ & $62.9 \pm 20.6$ & $24.6 \pm 4.2$ & $222 \pm 39$ & $141 \pm 89$ & $128 \pm 18$ & $78 \pm 11$ & $83 \pm 10$ \\
\hline \multirow[t]{2}{*}{ Arg/Arg } & $26.9 \pm 5.3$ & $65.6 \pm 22.2$ & $25.5 \pm 3.4$ & $226 \pm 46$ & $147 \pm 70$ & $134 \pm 16$ & $84 \pm 9$ & $84 \pm 12$ \\
\hline & n.s. & n.s. & n.s. & n.s. & n.s. & n.s. & n.s. & n.s. \\
\hline \multicolumn{9}{|c|}{ Females $(\mathrm{n}=103)$} \\
\hline Gly/Gly & $26.1 \pm 6.0$ & $67.4 \pm 21.3$ & $25.1 \pm 4.8$ & $223 \pm 44$ & $116 \pm 49$ & $133 \pm 17$ & $84 \pm 8$ & $84 \pm 11$ \\
\hline Gly/Arg & $24.5 \pm 6.4$ & $62.0 \pm 21.6$ & $23.4 \pm 4.2$ & $218 \pm 41$ & $108 \pm 54$ & $125 \pm 18$ & $78 \pm 16$ & $83 \pm 9.2$ \\
\hline \multirow[t]{2}{*}{ Arg/Arg } & $27.2 \pm 4.6$ & $66.5 \pm 21.3$ & $24.7 \pm 2.0$ & $229 \pm 49$ & $158 \pm 87$ & $139 \pm 19$ & $86 \pm 11$ & $88 \pm 12$ \\
\hline & n.s. & n.s. & n.s. & n.s. & n.s. & n.s. & n.s. & n.s. \\
\hline
\end{tabular}

Data are presented as means $\pm \mathrm{SD} . \mathrm{BP}=$ Blood pressure; $\mathrm{HR}=$ heart rate.

\section{Discussion}

With respect to the multiple interactions between the sympathetic nervous system and the HPA axis, we investigated 2 polymorphisms in the ADRA2A and the ADRB2 genes in relation to the ACTH and cortisol values of the DEX/CRH test in patients with major depression.

The major and unexpected findings of our study were gene-gender effects in the associations between adrenergic polymorphisms and HPA axis activity. Males homozygous for the ADRA2A -1291G allele showed increased ACTH and cortisol responses in the DEX/CRH test, both in the acute state of the disease and before discharge from hospital. In contrast, no effect of the ADRA2A polymorphism on basal or hCRH-stimulated ACTH and cortisol values could be observed in the female patient group. Concerning the ADRB2 Arg16Gly polymorphism, we found increased HPA axis activity in females carrying at least one 16Arg allele, with highest pretreatment ACTH and cortisol values in Arg/Arg homozygotes, and this increased response remained ele- vated before discharge from hospital. This study thus provides evidence that, depending on gender and genotypes in $\alpha$ - and $\beta$-drenoceptor genes, there might be a continuous HPA axis overdrive with increased ACTH and cortisol secretion, irrespectively of the actual status of depression.

There is no doubt that persistent alterations in cortisol exposure could result in target tissue pathology as occurs in chronically stressed or depressed individuals [1]. While the role of stress and the consecutive hyperactivity of the HPA axis is well established [7, 20], there is also recent evidence that high HPA axis reactivity to stress and increased tissue sensitivity to cortisol are associated with severe atherosclerosis [21]. Due to several studies, there is convincing evidence that the depressogenic effect of stress has some genetic underpinning, as carriers of the 5-HTTLPR S allele are more likely to develop depression in response to a stressful life event [22, $23,20]$. Another study has shown that among patients with chronic illness, carriers of the S allele are more vulnerable to depression, perceived stress and high norepi- 
nephrine secretion, and these factors may contribute to or worsen cardiovascular outcomes [24]. Although gender is increasingly perceived as key determinant in various disorders, systematic studies are still scarce. Concerning hormonal response patterns of the HPA axis, some recent papers pointed to gender differences in the reactivity to stress. Thus, it was shown by Heim et al. [25] that men with childhood trauma and current major depression exhibited increased ACTH and cortisol responses in the DEX/CRH test compared with nonabused men. It was further demonstrated that male subjects had a greater HPA axis response to a psychological stressor than female subjects, whereas women had a greater hormonal reactivity to pharmacologic stimulation [26]. Sex differences in ACTH pulsatility following metapyrone blockade were observed in another study, with men showing smaller ACTH AUCs than women [27]. The fact that highly anxious females exhibited lower cortisol release than highly anxious males further suggested that high trait anxiety females may be associated with an inability to respond with sufficient activation of the HPA axis under acute psychological stress [28]. Our observation that the ADRA2A and ADRB2 genotypes have differential effects on HPA axis function in males and females might be seen in context of the recent data. One possible explanation for the gene-gender interaction could be estrogen, a hormone which influences the activity of the HPA and SAM axes. Between puberty and menopause, women usually show lower HPA axis activity and autonomic responses than men of the same age. However, the response is higher in the luteal phase, when post-stress free cortisol levels approaches those of men. After menopause, there is an increase in sympathoadrenal responsiveness, and consequently estrogen replacement therapy reduces HPA activity and sympathetic nervous system activity [29]. Although in our study, we did not monitor the hormonal phases within the female cycle and we did not exactly distinguish between females being in the pre- or postmenopausal phase, we calculated the data separately for women below and above the age of 50 years. As expected, we found significantly increased systolic and diastolic blood pressure and triglyceride serum levels in the older group. We further found increased levels of $\mathrm{ACTH}$ and cortisol in the DEX/CRH test in females beyond 50 years. However, the fact that this difference was of marginal significance ( $p=0.08)$, the observed genegender effect of the ADRB2 Arg16Gly polymorphism is not likely to be explained by different levels of estrogen. Several limitations may be noted in this study.
Firstly, the number of male patients homozygous for the ADRA2A -1291G allele is rather low (6.9\%), and, in consequence, the explanatory power is not high. However, this low number is outweighed by the huge difference in the ACTH and cortisol values in GG homozygous males (peak ACTH $=51.3 \mathrm{pg} / \mathrm{ml}$; peak cortisol $=10.4$ $\mathrm{ng} / \mathrm{ml}$ ) as compared to the GC and CC genotypes (peak $\mathrm{ACTH}=18.8 \mathrm{pg} / \mathrm{ml}$; peak cortisol $=4.2 \mathrm{ng} / \mathrm{ml}$ ). Further, and maybe of more importance, is the fact that the HPA axis hyperactivity was not downregulated during treatment, thus indicating a continuously increased ACTH and cortisol outflow with all its consequences on metabolism, the vasculature and the immune system. A further limitation of our study is the fact that we did not consecutively follow up several physiological parameters such as weight, blood pressure and serum lipids in all patients, and thus we are unable to relate the polymorphisms reliably to these parameters. Moreover, many of the patients had been pretreated (despite a washout period of 5 days), and thus both the serum lipids and weight might have been altered.

In conclusion, although preliminary, our findings demonstrate the potential of genetic effects on the stress response system in pathological conditions such as depression. The ADRA2A -1291GG genotype was associated with increased HPA axis activity in men and the ADRB2 Arg allele with that in females. The fact that in carriers of the respective allele the increased ACTH and cortisol values remained elevated in remission provides evidence that, depending on gender and the polymorphisms, there might be continuous HPA axis overdrive. Considering the importance of cortisol in atherosclerosis, one might be tempted to hypothesize that these patients are at high risk of comorbidity between depression and cardiovascular disorders. In future, prospective studies including both patients groups are clearly warranted.

\section{Acknowledgements}

The results presented in this paper are part of the doctoral thesis of M.S. Part of this work was supported by a grant from the German Federal Research Ministry within the promotional emphasis 'Competence Nets in Medicine'. 


\section{References}

1 Chrousos GP, Kino T: Glucocorticoid action networks and complex psychiatric and/or somatic disorders. Stress 2007;10:213-219.

2 Pasquali R, Vicennati V, Cacciari M, Pagotto $\mathrm{U}$ : The hypothalamic-pituitary-adrenal axis activity in obesity and the metabolic syndrome. Ann NY Acad Sci 2006;1083:111128.

3 Rosmond R: Role of stress in the pathogenesis of the metabolic syndrome. Psychoneuroendocrinology 2005;30:1-10.

4 Frasure-Smith N, Lesperance F: Depression and coronary artery disease. Herz 2006; 31(suppl 3):64-68.

5 Mastorakos G, Pavlatou MG, Mizamtsidi M: The hypothalamic-pituitary-adrenal and the hypothalamic-pituitary-gonadal axes interplay. Pediatr Endocrinol Rev 2006;3 (suppl 1):172-181.

6 Smith SM, Vale WW: The role of the hypothalamic-pituitary-adrenal axis in neuroendocrine responses to stress. Dialogues Clin Neurosci 2006;8:383-395.

7 Holsboer F: Stress, hypercortisolism and corticosteroid receptors in depression: implications for therapy. J Affect Disord 2001; 62:77-91.

8 Modell S, Yassouridis A, Huber J, Holsboer F: Corticosteroid receptor function is decreased in depressed patients. Neuroendocrinology 1997;65:216-222.

9 Lima JJ, Feng H, Duckworth L, Wang J, Sylvester JE, Kissoon N, Garg H: Association analyses of adrenergic receptor polymorphisms with obesity and metabolic alterations. Metabolism 2007;56:757-765.

10 Zhu H, Poole J, Lu Y, Harshfield GA, Treiber FA, Snieder H, Dong Y: Sympathetic nervous system, genes and human essential hypertension. Curr Neurovasc Res 2005;2:303317.

11 Ruhe HG, Mason NS, Schene AH: Mood is indirectly related to serotonin, norepinephrine and dopamine levels in humans: a metaanalysis of monoamine depletion studies. Mol Psychiatry 2007;12:331-359.

12 al Damluji S: Adrenergic control of the secretion of anterior pituitary hormones. Baillieres Clin Endocrinol Metab 1993;7:355392.
13 Rosmond R, Bouchard C, Bjorntorp P: A C$1291 \mathrm{G}$ polymorphism in the alpha $2 \mathrm{~A}^{-}$-adrenergic receptor gene (ADRA2A) promoter is associated with cortisol escape from dexamethasone and elevated glucose levels. J Intern Med 2002;251:252-257.

14 Mezey E, Reisine TD, Palkovits M, Brownstein MJ, Axelrod J: Direct stimulation of beta 2 -adrenergic receptors in rat anterior pituitary induces the release of adrenocorticotropin in vivo. Proc Natl Acad Sci USA 1983;80:6728-6731.

15 Large V, Hellstrom L, Reynisdottir S, Lonnqvist F, Eriksson P, Lannfelt L, Arner P: Human beta-2 adrenoceptor gene polymorphisms are highly frequent in obesity and associate with altered adipocyte beta- 2 adrenoceptor function. J Clin Invest 1997;100: 3005-3013.

16 Pereira AC, Floriano MS, Mota GF, Cunha RS, Herkenhoff FL, Mill JG, Krieger JE: Beta2 adrenoceptor functional gene variants, obesity, and blood pressure level interactions in the general population. Hypertension 2003;42:685-692.

17 Masuo K, Katsuya T, Fu Y, Rakugi H, Ogihara T, Tuck ML: Beta2-adrenoceptor polymorphisms relate to insulin resistance and sympathetic overactivity as early markers of metabolic disease in nonobese, normotensive individuals. Am J Hypertens 2005; 18: 1009-1014.

18 Hindorff LA, Heckbert SR, Psaty BM, Lumley T, Siscovick DS, Herrington DM, Edwards KL, Tracy RP: beta(2)-Adrenergic receptor polymorphisms and determinants of cardiovascular risk: the Cardiovascular Health Study. Am J Hypertens 2005; 18:392397.

19 Bornstein SR, Schuppenies A, Wong ML, Licinio J: Approaching the shared biology of obesity and depression: the stress axis as the locus of gene-environment interactions. $\mathrm{Mol}$ Psychiatry 2006;11:892-902.

20 Mann JJ, Currier D: Effects of genes and stress on the neurobiology of depression. Int Rev Neurobiol 2006;73:153-189.

21 Alevizaki M, Cimponeriu A, Lekakis J, Papamichael C, Chrousos GP: High anticipatory stress plasma cortisol levels and sensitivity to glucocorticoids predict severity of coronary artery disease in subjects undergoing coronary angiography. Metabolism 2007; $56: 222-226$.
22 Caspi A, Sugden K, Moffitt TE, Taylor A, Craig IW, Harrington H, McClay J, Mill J, Martin J, Braithwaite A, Poulton R: Influence of life stress on depression: moderation by a polymorphism in the 5 -HTT gene. Science 2003;301:386-389.

23 Cervilla JA, Molina E, Rivera M, TorresGonzalez F, Bellon JA, Moreno B, Luna JD, Lorente JA, Mayoral F, King M, Nazareth I, Gutierrez B: The risk for depression conferred by stressful life events is modified by variation at the serotonin transporter 5HTTLPR genotype: evidence from the Spanish PREDICT-Gene cohort. Mol Psychiatry 2007;12:748-755.

24 Otte C, McCaffery J, Ali S, Whooley MA: Association of a serotonin transporter polymorphism (5-HTTLPR) with depression, perceived stress, and norepinephrine in patients with coronary disease: the Heart and Soul Study. Am J Psychiatry 2007; 164:13791384.

25 Heim C, Mletzko T, Purselle D, Musselman DL, Nemeroff CB: The dexamethasone/corticotropin-releasing factor test in men with major depression: role of childhood trauma. Biol Psychiatry 2008;63:398-405.

26 Uhart M, Chong RY, Oswald L, Lin PI, Wand GS: Gender differences in hypothalamic-pituitary-adrenal (HPA) axis reactivity. Psychoneuroendocrinology 2006;31:642-652.

27 Young EA, Ribeiro SC, Ye W: Sex differences in ACTH pulsatility following metyrapone blockade in patients with major depression. Psychoneuroendocrinology 2007;32:503507.

28 Takai N, Yamaguchi M, Aragaki T, Eto K, Uchihashi K, Nishikawa Y: Gender-specific differences in salivary biomarker responses to acute psychological stress. Ann NY Acad Sci 2007;1098:510-515.

29 Komesaroff PA, Esler MD, Sudhir K: Estrogen supplementation attenuates glucocorticoid and catecholamine responses to mental stress in perimenopausal women. J Clin Endocrinol Metab 1999;84:606-610. 